JEA

60,3

340

Received 9 April 2021

Revised 15 July 2021

22 August 2021

Accepted 15 September 2021

\section{Democratic governing ideals and the power of intervening spaces as prerequisite for student learning}

\author{
Olof Johansson and Helene Ärlestig \\ Centre for Principal Development, Umeå University, Umeå, Sweden
}

\begin{abstract}
Purpose - In the rational model of the democratic governing chain, intervening spaces at all levels are neglected in relation to the policy process. An intervening space is a group of persons with the power and responsibility to interpret policy at their level in an organization. The research question is as follows: How are democratic policy ideas visible in the intervening spaces of a governing chain in public schools?

Design/methodology/approach - The study is based on two municipalities representing the 25 most populated cities in Sweden. The data are based on interviews with 66 informants with leadership roles on the district level and two schools in each municipality.

Findings - Leadership is obviously more than making decisions. It is also about facilitating and creating trust, engagement, motivation and willingness to take responsibility. In this process, intervening spaces are central. They exist at all levels from the national ministry to the classroom. The empirical examples show the importance and challenges in how different leadership roles, relationships and interaction transform policy intentions to practice on the local level.
\end{abstract}

Originality/value - The authors contribute by highlighting the parallel interpretation processes that take place at various leadership levels locally. There are possibilities and challenges in aligning the intervening spaces into a rational governing chain. The findings indicate that intervening spaces and policy drift is vital to support, control and use professional competence in the process to transfer political ideas to classroom practice.

Keywords Governing chain, Organizational structures, Organizational culture, Leadership,

Intervening spaces, Democratic ideals

Paper type Research paper

\section{Introduction and purpose}

This article examines how national educational policies are affected by intervening spaces in the Swedish school system governing chain. In the rational models of the governing chain, intervening spaces at all levels are neglected in relation to the policy process. We argue that their importance has increased because of democratic organizational ideals such as governing by relationships, trust, inclusion and equity.

An intervening space is a group of persons with the power and responsibility to interpret policy at their level in an organization. Such actors understand and form new policies, routines and activities to transform ideas into actions. These groups can have a formal function in the organization or they can comprise informal groups in the governing chain. An important aspect in a democratic culture is to recognize that there are multiple voices and perspectives on how to reach a common ideal society. They can also be seen as a prerequisite for realization of national policies in local schools.

Democratic values are ideological fundamentals in many societies. They raise issues regarding how to balance respecting the individual and pursuing the best outcome for all

(C) Olof Johansson and Helene Ärlestig. Published by Emerald Publishing Limited. This article is published under the Creative Commons Attribution (CC BY 4.0) licence. Anyone may reproduce, distribute, translate and create derivative works of this article (for both commercial and non-commercial purposes), subject to full attribution to the original publication and authors. The full terms of this licence may be seen at http://creativecommons.org/licences/by/4.0/legalcode. 
citizens (Rothstein, 2000). This causes debates on equality, inclusion, individual choice and opportunities.

Because schools reflect and educate the next generation of adults, we analyze how democratic ideals, norms and values in educational policy documents are visible in school leaders' intervening spaces in the governing chain. The empirical observations derive from two Swedish school districts. Our research question is as follows:

$R Q 1$. How are democratic policy ideas visible in the intervening spaces of a governing chain in public schools?

The literature on leadership in public-sector organizations is usually oriented toward the function of school leaders in administration and their accountability for student outcomes (e.g. Leithwood and Azah, 2017; Gu et al., 2018). Educational policy improvement has been a research area for many years (Lawn and Lingard, 2002). Often the results indicate what is successful or not in a specific process or event. We contribute by highlighting the parallel processes that take place simultaneously at various leadership levels. Ideals such as inclusion, transparency and involvement create opportunities and challenges related to turning ideas from one level into actions at the next. Actors in formal leadership positions are expected to use both managerial and leadership abilities to reach decided goals and obtain results above expectations. The formal and informal interactions between leaders in the same school organization form priorities and working conditions within the system.

By describing and analyzing how politicians, superintendents and principals in public (municipal) schools think about their leadership in relation to the context in which their leadership is situated, it is possible to acquire a deeper understanding of how local actors use intervening spaces to realize policy intentions. We assert that policy drift is inevitable, necessary and positive in the governing chain. Powerful intervening spaces create motivation and engagement that is necessary to realize policy intentions in practice. These activities in the intervening spaces bind intentions and practice. One reason to highlight the intervening spaces is that many of the interactions in organizations are complex, sensitive and taken for granted. How one level communicates and relates to another can contribute to higher achievement or to conflicts and mistrust.

Following Karen Louis's interest in the learning cultures of school systems and how professional communities are developing organizational learning and trust to improve student learning (e.g. Leithwood et al., 2012; Louis and Lee, 2016; Murphy and Louis, 2018), we argue that studies on educational leadership should consider context at all hierarchical levels. By context, we mean both the local setting in which the municipality and/or local schools work and what national policy constitutes (Louis and Smith, 1991). The logic and guiding principles behind the governing system is part of the context. These democratic principles should guide both political decision-making and political leadership and should also be used as guiding principles for civil servants such as superintendents, principals and teachers. In the Swedish case, one basic principle is that teaching and administration follow the democratic principles and respect the intrinsic value of all individuals. The system of governing has the potential to facilitate and constrain different types of leadership ideals and actions in relation to democratic and participatory practices, as well as accountability and control. This makes the relationship between the formal rational governing structures of policy and the more informal power of the intervening spaces an interesting knowledge area.

\section{The empirical study design}

We used a mixed method approach. The qualitative data are a set from in-depth interviews conducted with actors in the governing chain at the municipal level.

Democratic governing ideals 
JEA

60,3

342

Our data set comes from a study conducted in two municipalities representing the 25 most populated cities in Sweden. The study was conducted during two research visits to each city conducted eight months apart. The first visit was aimed at providing an initial overview of leadership roles and organizations. This was complemented with official documents and statistics. In the second data collection, we conducted interviews with leaders on the district level and two schools in each municipality. We conducted interviews with superintendents $(n=2)$, deputy superintendents (area managers; $n=5)$, politicians related to governance of education at the municipal level $(n=4)$, quality assurance coordinators $(n=4)$, principals $(n=4)$, assistant principals $(n=5)$, school secretaries $(n=2)$, first teachers (teacher leaders; $n=11)$ and teachers $(n=29)$. Of the interviews, 41 were conducted as individual interviews, and 9 were organized as group interviews, for a total of 66 informants. All informants hold leadership positions in the local governing chain. Two researchers conducted each interview. One researcher asked questions, while the other took notes and supported with additional probing questions. All interviews were recorded and transcribed.

To obtain a more nuanced understanding of relationships and interactions, we completed the interviews with a visual exercise (Grimm et al., 2021). During the interview, we had a large blank paper divided into three sections and put an adhesive note with the interviewee's name in the middle. We then asked the person to think about their organization and that an organization has several organizational leadership levels which were symbolized by the lines on the paper. They were informed that they could move their own name to the most appropriate place. Thereafter we asked them to add notes with the names of persons with important functions as well as colleagues at their workplace. Our purpose in visualizing these relationships was to reflect with the respondent on formal roles and expectations in relation to individual experiences of their understanding of the power relations and their relationship with the formal structure.

School institutions are dependent on the local context. A focus on interactions and relationship can contribute to a larger understanding of both the whole system and its parts (Shaked and Schecter, 2017). In this article, our intention is not to compare or understand the relationship within each municipality or local school. Instead, we have used the empirical data to give examples of the dynamics and interactions on both vertical and horizontal organizational levels.

\section{The Swedish school system - a bird's-eye view}

In most countries, various laws and policy documents contain mission statements that describe the purpose of schools, as well as an education policy describing how the associated goals should be achieved. Most of those statements contain two overarching missions: passing on knowledge from one generation to the next and facilitating the upbringing of good and harmonious citizens who can lead and continue to develop democratic societies. Those goals can only be fulfilled in schools that take full responsibility for ensuring that students acquire and develop the knowledge that is necessary for each individual's understanding of what a democratic society means and what the alternative could be.

The Scandinavian countries have generally been represented as having a distinctive type of education system that is strongly influenced by a social democratic ideology embodying the comprehensive values related to providing education for all, fostering support for democratic values and emphasizing the equality of opportunities (Trujillo et al., 2021). This view of education has been and remains an issue for continuous debate, both endogenous and exogenous (Ozga et al., 2011; Gunter, 2016). This has led to changes in how education is planned and carried out in all Scandinavian countries. Some scholars argue that there has 
been a move away from collectivist, comprehensive values toward more individualist values (Lundahl, 2012; Leo, 2013; Pashiardis and Johansson, 2020).

The national expectations are that school leaders will adjust their leadership in relation to shifting policy focus and societal changes. When politicians in the parliament make new national policy decisions, their mission is almost always based on the desire to improve schools. Therefore, they want implementation to be quick and effective (Lundgren, 2012).

For many years, there was little or no discussion about the role of leaders as models in relation to educational policy change. If the goal of national policy is to create democratic schools that foster the next generation, there is a need to review the style of leadership used in the schools. Students should not only learn about democracy but also experience democracy during the school day (Leo, 2013).

In research, there is a great deal of evidence that school leaders are important change agents (e.g. Day and Leithwood, 2006; Louis, 2013; Ärlestig et al., 2015). How leadership is practiced in relation to staff and other leaders in the formal structure is important for the quality of policy application and practice changes. Teachers' behavior and priorities in their practice with students is vital to their work with new policies. Lately, in many countries, there has been a focus on how teacher teams can improve activities with students through collective learning in professional learning communities (Stoll and Louis, 2007; Timperley, 2011). These teacher teams can also be viewed as intervening spaces and are, as such, of interest for our understanding of the governing chain.

In the late 1970s, a decentralization process began in Sweden that increased municipalities' ownership of schools. This occurred gradually, but the process was complete by the time the new school law was accepted in the early 1990s. Decentralization was key, so the state started giving lump sums to the municipalities to finance the local schools. At the same time, the municipalities could support the schools with additional local tax money. The municipality acquired full responsibility for organizing and implementing school activities in 1991. This included the municipality's becoming the employer of and responsible party for principals and teachers and the daily work done in schools (Johansson and Arrlestig, 2022).

In 1992, independent schools were introduced in Sweden and were given the same rights as public-sector schools to work; they were financed by a voucher system from the municipalities. The following year, Sweden granted parents the right to free school choice, including public and independent schools within the municipality in which they lived. This gave the municipality a new role: It would now both own the public schools and transfer student financial vouchers to the independent schools in the community (SOU, 2015:22).

On the more ideological side of the school policy, it was clear that the schools should give the students the knowledge necessary to become citizens. Students should be trained in and be able to think in democratic ways and should respect that all people are equally important. They should also be informed, so they can make active individual choices and know how to participate and be involved in issues they consider important. This was expressed clearly as a central task for teachers and principals.

The different reforms did not meet the intended expectations which underline that the work and quality of the intervening spaces had not received enough attention. Different political intentions regarding how to solve issues give power to the intervening spaces in the chain of government. We discuss enactment processes at the school level, but there are important intervening spaces at all levels in the chain of government, and these do not always apply to a rational implementation process. In one early publication, political scientists Pressman and Wildavsky (1984) pointed out that laws are implemented by persons who have different understandings of their meaning and who sometimes do not view the decision as important for effective implementation. This study was followed by many more implementation studies both internationally and locally in Sweden, and our study follows in their tradition. People having different understandings of policy happens in schools all the
Democratic governing ideals 
JEA

60,3

344

time in relation to the teachers' freedom to teach, as well as principals' and superintendents' priorities. There is a drift in understanding every time an implementation process moves from a political decision to an administrative process (Johansson and Arlestig, 2022).

The challenges in the governing process underline the importance of intervening spaces. The actors in these spaces have the power at their level in the governing chain to adjust the intention with local policy. These adjustments start a policy drift to transform policy ideas into local context and prerequisites for classroom teaching.

\section{National educational policy meets local implementation structures}

Leithwood et al. (2012) claimed that

Features of state and district policies, practice and other characteristics interact with one another and exert an influence on what school leaders do (p. xxvi).

This quotation promotes thinking about how national education policy in Sweden influences relationships, responsibility and leadership at all levels. The state has a central function of formulating laws and regulations, but these laws can be interpreted in various ways. In Sweden, the state also includes five government education agencies. The most important are the National Agency for Education and the State School Inspection Agency. These play a central role in interpreting the laws and issuing regulations that explain the laws' intent and the actions expected to be carried out in schools. This is the first level for intervening spaces in which all civil servants in the agencies have power to affect the interpretation of the laws.

The next level in the hierarchy is the school district - in Sweden, often equal to the municipality - which is the receiver of the national policy. The municipality's political functions involve the municipal council and the school board. At both of these levels, civil servants help the politicians make decisions. This is another intervening space with the power to interpret policy.

The decisions they make begin the process of governing how their policy decisions should be handled by school leaders and teachers to achieve the best possible learning outcomes for students in their districts and schools.

There are, of course, other stakeholders and conditions that affect the outcomes. Sweden, for instance, has very strong unions for teachers and school leaders. They affect policy by defending the labor market agreements they have for school leaders and teachers. If policies would affect those agreements, they can always ask for new negotiations, so they are actors who are part of the policy drift. Other stakeholders, such as parents and students, can be actors in intervening spaces with the ability to affect processes and outcomes.

Between every decision level in the local system, there is an intervening space comprising a group of actors with the power to interpret and adjust the intentions of national policy. According to their understanding, they create activities and new documents for the next level. An important criterion for the intervening space is that it can affect interpretations both upward and downward in the organization. In earlier implementation research, there is little discussion of the power of these intervening spaces. Instead, the focus has been on how various layers in the organization obstruct the implementation process. Examples include how actors delay the process, do less than is expected and forget the new method and return to the old ways as soon as possible (Sannerstedt, 2000). These delaying actions still exist, but they must be understood in relation to the policy drift that occurs. However, intervening spaces can also be effective links in the chain where collaborative learning, sense making and the improvement of mindsets in relation to new policy can be the start of new actions (Stoll and Louis, 2007; Weick, 1976).

To understand the complexity of agencies, how various levels below them work, and their effects at the local level, several perspectives are necessary (Ärlestig and Johansson, 2020; Moos and Paulsen, 2016). Ball et al. (2012) argue that 
Policies rarely tell you exactly what to do, they rarely dictate or determine practice, but some more than others narrow the range of creative responses. (p. 3)

They use the term "enactment," which is visible in the intervening spaces. In addition, Ball et al. focus on the will, rights and responsibilities of individuals in an organization as they relate to being creative and working for the best possible results within given parameters. Enactment, or the effecting process, depends on the bureaucratic structure and culture of the educational organization and must work such that they can, in their intervening space, create trust for the actions and interpretations of the various policy decisions they propose.

In the next section, we elaborate on and give empirical examples of relationships and interactions in intervening spaces in two municipalities.

\section{Our empirical case and its local governing spaces}

In Sweden, a high number of reforms, together with an increasing focus on control and accountability, have contributed to an increase in the number of leaders during the last decade. Notable here is that the number of leaders that have increased most is different kinds of middle leaders below the top leaders. This fact has a direct effect on the intervening spaces in the policy chain (Johansson and Ärlestig, 2022). How leaders interact builds partly on the structure and culture of the organization and partly on the historical experience of various attempts to organize for improvement. As shown in earlier research, organizational structure and culture are dependent on each other and are prerequisites for leadership (Höög et al., 2005). At all levels, we find statements on how structure and culture form and are formed by individual leaders and their relationships and interactions with other leaders and staff members in the intervening spaces. The empirical data are examples of how the interaction within the intervening spaces creates both possibilities and challenges. Individual actors' agency, competence and abilities will be mixed with organizational prerequisites which again highlight the complexity that forms actions within organizations. Our empirical data revealed similarities, and it was not unusual that superintendents, principals and first teachers gave similar answers even if they did not work in the same municipality or school.

\section{Democracy and hierarchy}

Both municipalities have a hierarchal organization in which leaders at various levels are the main communication channels upward and downward. This is especially apparent in relation to managerial issues. As the number of actors grows, the interaction and processes become more intertwined and complex. To be able to simultaneously administer ongoing work and implement new policy, it is necessary to combine a focus on efficiency and accountability with building relationship and trust. The intervening spaces often involve a mix between handling current problems and work for school improvement. This was described to us by a principal as building a roundabout in rush traffic.

The superintendents gave examples of the importance of trust. At the same time, they ask for clarity and control. One way to combine these strategies is to focus on the process:

I do not control the employees in terms of whether they act appropriately. Instead, I hope it will be viewed as support. Sometimes I am engaged early in the process where they need my support, and at certain stages, I need feedback. (Superintendent Al)

This reveals that it is necessary to allow other leaders to interpret and form their own strategies within certain frames. The superintendents are in turn dependent on their relationship with the chair of the political school board. By devoting a lot of time to formal and informal communication with the chair, they are able to prepare the board and contribute to knowledge about today's problems, national policy requirements and what is 
JEA

60,3

happening in the local schools. They use the intervening space and their close relationship with the chair to influence politicians' decision-making which, if successful, provides a good basic and updated understanding without being captured by politicians in detail. It is important to maintain the logical gulf between the politicians' "what" and the superintendent's power over "how":

Even if we have a large district, which is an advantage, because we have students of all ages, there are no boundaries or organizational gaps, as it was when we had a separate board for high schools, so this is a fantastic structure. (Chair of the Political Board, Anna)

The chairs verified the importance of frequent communication and daily conversations help to keep track of processes and contribute to a strong governing chain. They are eager to take responsibility but also to influence the schools in relation to what they promised voters in earlier elections. The superintendents reported that it is difficult for politicians to work with limited resources, so the purpose of civil servants is to work closely with the board and give them information and arguments so they can choose the best way forward. This process helps politicians to make more sustainable decisions.

A conscious effort, along with dialogues and a close relationship with the political side, leads to shorter district action plans with prioritized objectives. In one of the municipalities, the action plan is only eight pages long and builds on three main political goals. Together with the schools' quality assessment report, the superintendent has formulated 15 mission statements that are included in the action plan. The next step is for the deputies to form an action plan. From there, the principal writes an action plan for the local school.

The action plan is an example of how general political ambitions are concretized at each level. Instead of having too many detailed objectives at the highest level, each level forms its own plan in relation to the previous level's action plan. The superintendent sees this as a form of trustful leadership that creates engagement at all levels. This is an example where local policy creates frames in the intervening spaces that contributes to control as well as support in how issues are interpreted on different levels. It also verifies the challenge of balancing how specific or broad leaders should be to create support, directives and engagement for the next level of leaders.

The district controller verifies that the plans create a structure that considers both the full picture and the parts (Shaked and Schechter, 2017):

It contributes to consensus and to understanding how the parts are connected, the dialogues build on each other, the various plans are made, and the activities are performed. I see that the politicians also participate and understand the various parts. (Quality Controller, Astrid)

The principals feel that they have considerable maneuvering room. Because their role involves a combination of state regulations and municipality prerequisites, they argue that they need to work with the deputy principals to shape the state policy to fit the local structure and culture. This means that interpretations can differ between schools even in the same school district.

One of the principals gave an example of when she uses intervening spaces to benefit her school. At the same time, she clarified that there is risk in advocating for what you believe will benefit local needs and values. She stated, for example, that if the school inspectorate would perform an unannounced inspection, they would probably find deficits related to the freedom given to teachers, but that is part of the game.

When the organization is at its best, leaders play roles at several levels and become brokers. They can combine managerial requirements and improvement intentions. Being a leader who participates in this way provides an information advantage, as well as access to meetings where it is possible to discuss decisions and directions with other principals and 
district leaders. This is an ongoing work that also creates conflicts even when there is frequent communication.

\section{Communication, interpretations and relations}

In large school organizations, general intentions and abstract policies are translated into actions in classrooms and local schools. Seeing how the work and relationships depend on and are connected with each other can be difficult. Even if there is a division between administrative and educational issues, they are dependent on each other. How the actors on the various levels refer to what is decided or happens on other levels can help with the interpretation and understanding of the many different aspects that impact processes. Most teachers have and should have their focus on students and their learning. At the same, time a broader organizational understanding of their role and relationship in and to the intervening spaces helps them in their mission. This requires an ability to communicate, so each level that is involved benefits from information from the others:

It goes without saying that, at this school, the deputy principal is a part of the teacher team. (Teacher Leader, Eve)

In the best situation, employees do not feel that they work in a hierarchical organization. Instead, it is an organization with multiple roles and forums that interact. When all these roles and functions form an intervening space, it sometimes develops a focus on improvement but at other times the intervening space creates "a good enough" group when the leadership within the space is weak.

Teacher leaders have important roles both horizontally and vertically. In Sweden, egalitarianism is the norm among teachers (Grimm, 2020), which can make it difficult to be critical toward colleagues. As in many other places, professional learning communities have been viewed as a way forward in Sweden. At many schools, mutual conversations tend to stay at a level where encouragement and ideas are in focus rather than deep and challenging conversations. One teacher leader expressed the following opinion:

I am not there to tell anyone what they should do. I can coach them in a positive way, so we are heading in the same direction. (Teacher Leader Lena)

Teacher leaders see each other primarily as colleagues who support each other and avoid discussions in which they need to make decisions that not all agree with this is a problematic side of leadership between colleagues when the teacher leaders do not understand that leadership is about creating understanding for improvement. They are not interested or involved in the managerial side of leadership as many principals and district leaders are. At the same time, they have no problem defining themselves as leaders in the classroom with an ambition to involve the students:

The most important part is that the student feels secure in the classroom. They should know that I, as their teacher, decide even if we do it together. I believe in clear instructions, and they know what I expect from them, which creates a safe environment in the classroom. (Teacher leader Lisa)

Teachers clearly focus on the students and colleagues. They depend on the idea that daily relationships and activities remain as smooth as possible. Their knowledge about work at the political and district level is limited. They seldom meet representatives from that level and are generally more focused on issues connected to the local schools' prerequisites and culture. If the district and their leaders do not affect their work negatively, they are comfortable with the division of tasks. In these schools, the principal and teacher leaders become facilitators more than leaders. In the intervening spaces, the content takes different forms depending on the actor's role and mission. Once more the "good enough" perspective becomes hindering for school improvement.
Democratic governing ideals 
JEA

60,3

348

Relationships in and between the intervening spaces

A governance chain requires formal leaders to balance expectations from all intervening spaces. For a superintendent, it is not possible to be too detailed regarding how the organization should handle various issues.

I think that we need to do this together, so I need to work through my deputy superintendents. If I have my own ideas, it only becomes messy [...]. [...] If I met the principals and started leading and making decisions, it would become disorganized. Instead, I listen and try to understand their prerequisites and what challenges they have. That is necessary so I can bring knowledge back and make the right decision at the district level. I need to avoid governing where the principal is responsible. (Superintendent Mary)

This statement shows like the other interviews do, that the school leaders have good intentions. They are eager to support their coworkers. At the same time, their different intervening spaces - both formal and informal - with coworkers involve various expectations and needs and want to have some power over their situations. Principals are expected to be clear and govern while motivating, distributing leadership and encouraging teacher leaders and teachers to take the initiative and act independently.

And in general, which I am in the middle of, I wonder how much pressure should there be? How many requirements should there be in an improvement process? How much should I pressure the individual actor? How much should I push and pull? This is a hard balance to find so it is necessary to be sensible. A competent principal need to be clear and have the ability to [. . . take inputs, sort them and continue the process from that. (Principal Betty)

In the intervening spaces, there is seldom clear answers on how to proceed instead it is a forum forming the processes together. This can also be described as modeling through and finding acceptable positions. A deputy superintendent claimed that even if there is regular interaction between the levels, there are aspects of the work that are impossible to understand if one does not work at the level in question.

I can only talk from my own experience, but when I worked as a principal, I thought I understood how governance was organized at all levels, but I did not, not in the way I understand it now. Now I understand it in a totally different way. (Deputy Superintendent, Fred)

This superintendent realized that each intervening space in an organization can have its own culture and ambitions which do not have to be the same as the organizational purpose.

A principal said that he also expected his employees to listen and balance what is expected of students and parents. The coworkers needed to feel included and to have the possibility to affect processes and activities.

One deputy principal remarked that, especially when it comes to problem-solving and current problems, it is necessary to listen and sustain relationships rather than to make promises and solve the problems alone:

It is a balance: listen, say just enough and promise nothing. Instead, promise to come back and continue the dialogue. Make them feel seen and listened to, regardless of whether they are parents, students or teachers. (Deputy Principal, Maria)

This deputy principal recognizes that the intervening spaces in the organization have power both to obstruct leadership and when working cooperatively they have the power to enhance the ongoing processes.

All these extracts show the importance of building and sustaining relationships between leaders through the intervening spaces. This creates possibilities to work toward the same mission using competence on all levels. This requires a combination of setting directions, independence and being able to follow others. 
It can be challenging in a traditional top-down organization to foster independence, when each level uses its ability to make decisions. If the level above is too detailed and directive in its leadership, it is sometimes easier to let someone else make a decision than to use the intervening space to create a common understanding and take responsibility for the solution. When the intervening spaces work at their best, they create understanding and new knowledge about how the organization works in relation to its mission. One of the deputy principals gave an example where the discussion in itself helped the teacher team to become more independent. At first glance, a simple question can evoke a broader discussion on teaching, and learning and how to act with one voice, a discussion that contributes to form culture and mutual respect:

Members of the teacher team were going to take the students to a movie. The big question was whether the students could bring candy. They saved the question until the end of the meeting to be sure that I would be there and tell them my opinion. I said, "I think this is your decision," and it took three conferences before they decided. It was a good process in which everyone had to buy in, even if they were of another opinion, and even if it had been very easy for me to make a decision about the actual question. (Deputy Principal)

This deputy principal's decision not to interfere in the responsibility given to the intervening space of teachers was an important sign to the group that they cannot transfer difficult decisions to the next level of leaders. They must make all the decisions for which they have been given responsibility.

During hierarchical and vertical meetings, much time is spent on problem-solving and current issues. An important perspective in relation to intervening spaces is that they form coming activities. This is done in relation to both how they are structured and their content. One school has a yearly vision day during which each teacher team meets with the deputy principal and principal. This is appreciated by both the principal and the teacher teams:

We focus completely on our everyday work during weekdays, so we try to begin the year with a vision day on which we leave the school and talk about school improvement. The discussion during these days comes back up throughout the whole year. (Deputy Principal Rose)

This example shows how a single meeting becomes a reference for what a group has decided in relation to the expectations for the coming year. Taking time to together interpret and put expectations in words acknowledges the mutual work. This is an example of how agreement between different intervening spaces can become a commitment of importance for directing school improvement over time.

\section{Conclusion}

This article discusses the intervening spaces that are necessary for converting policy intentions into practice. During the last decade, with the importance of efficiency and accountability, we have seen a growing number of actors in the governing chain from national politicians to classroom actors (Pashiardis and Johansson, 2016; Arlestig and Johansson, 2020).

Democracy cannot be taken for granted even in a stable welfare country such as Sweden. Many policy reforms have implications for how resources are distributed and how to prioritize missions. Societal changes, together with ambitious political intentions, lead to reforms that must be interpreted and transformed into action at the local level. These processes involve many organizational levels and require further research (Norqvist and Ärlestig, 2021).

The link between the policy developments we described at the beginning of the chapter and the opinions expressed by local actors in the school system support the idea of a
Democratic governing ideals 
JEA

60,3

democratic school system, a system where actors on all levels have an important role in realizing the ambition to give all students a high-quality democratic learning experience and democratic school experience. For that to happen, all actors working in schools must understand the concept of democratic schools and work accordingly in relation to their leaders, staff, colleagues and students.

This needs to be mirrored in the leadership processes, as they model the behavior within the organization which includes involving and engaging actors on all levels. In our interviews, the respondents verified that they strive toward inclusive and trustful relationships in which support is the main aim.

Our results mainly affirm and point at the importance of leaders taking intervening spaces into account. Without an understanding that interaction and interpretations will determine the quality of both processes and results, there is a high risk that important initiatives and reforms will not be sustainable. This is visualized through comments such as "We need to do this together," which indicates that, in this case, the superintendent recognizes the knowledge and ability at the local school level.

Even if leaders on all organizational levels have good intentions, it seems that leaders have an implicit understanding of the importance to translate and interpret each levels understanding and mission. Intervening spaces open up for handling conflicting understanding and priorities. How relationships and interactions are built will determine how successful the organization is to engage and use all levels knowledge and work.

The superintendent's leadership will determine whether there is enough dialogue and room to maneuver at the lower levels. The superintendent's role becomes more of a facilitator than a manager in principle's enactment of various challenges. As a leader, it becomes important to foster both independence and loyalty at the same time. This is possible in intervening spaces that have the same goals and embrace the democratic ideals that also should be visible in the classroom.

All groups verified that horizontal conversation and informal dialogues between colleagues in intervening spaces is important in forming and moving the process forward. Such spaces clarify aims and intentions and form arguments, actions and teaching content for students. These meetings help to strengthen and make each level more independent and still working within the organizational frames. Here, the vertical meeting plays an important role because they can visualize perspectives from several organizational levels. They also help to use managerial resources and decisions to support educational challenges.

Statements at the school leadership level demonstrated the importance of involvement and being heard, which is a foundation of democracy. Remarks such as "It was a good process in which everyone had to buy in even if they were of another opinion" focus on processes that involve everyone instead of the single leader making a decision by himself. Through conscious actions, the principal empowered the teachers and gave them responsibility for the situation. Even if there are different understandings and conflicts, leadership relationship and interaction will determine how other actors will perceive the challenges that all organizations have. It is obvious that without intervening spaces or if they are poorly handled, there will be gaps and mistrust between actors which will obstruct the ideas of a democratic school where all actors are respected and take responsibility for their assignments.

In the strict formal local governing structure, it is obvious that the chair of the political board, the superintendent, the principals and the teacher leaders exhibit variation in terms of accountability and support. The deputies and teacher leaders talk much about policy changes related to coaching and problem-solving, whereas the chair, superintendent and principals tend to return to organizational objectives and results. A challenge is to balance the current problem-solving with strategic processes. A superintendent described his leadership as follows: "Sometimes I am engaged early in the process when they need my support." In this 
way, he gave the principals his trust and the possibility of taking responsibility and showing that they had the competence and professional skills to solve the problem.

Taking time to involve actors and to interpret and create policies that allow the next level to make their own interpretations is necessary for sense making and engagement. Providing enough time and balancing information, interpretation and control to move processes forward is a continuous challenge.

It is natural that leaders focus on the interactions and relations with the coworkers who are close to them. To take responsibility for the whole organizations development, it is necessary to increase the understanding of how interpretation and involvement helps to translate general and abstract goals into practice. The process of making schools more democratic started in the 1950s, and it has been in focus ever since. Now we can see changes in how schools are governed. In the formal model, the governing chain of the educational sector has no boxes for intervening spaces when described in rational terms. In our analysis, leadership is obviously about more than making decisions. It is also about facilitating and creating trust, engagement, motivation and willingness to take responsibility. In this process, can a continuous work with intervening spaces on all levels make it possible (Johansson and Ärlestig, 2022). Our empirical data for this research are from the local level, but the intervening spaces have the same function even at higher levels in the national educational system.

School organization will always have improvement areas and challenges. Leaders with different opinions and competence secure a vivid discussion. This is a part of healthy organizations and should have more attention. To fully understand leadership and organizations, it is necessary to sometimes focus on parallel processes and how these contribute to overlaps and gaps. More research on what creates tensions and how these are handle in intervening spaces can give more knowledge on democratic processes and how organizations work to create support, control and use professional competence at all levels.

\section{References}

Ärlestig, H. and Johansson, O. (2020), Educational Authorities and the Schools: Organisation and Impact in 20 States, Springer, Cham.

Ärlestig, H., Day, C. and Johansson, O. (2015), A Decade of Research on School Principals: Cases from 24 Countries, Springer, Berlin.

Ball, S.J., Maguire, M., Braun, A., Hoskins, K. and Perryman, J. (2012), How Schools Do Policy: Policy Enactments in Secondary Schools, Routledge, London.

Day, C. and Leithwood, K. (2006), Successful Principal Leadership in Times of Change: An International Perspective, Springer, Dordrecht.

Grimm, F., Norqvist, L. and Roos, K. (2021), "Exploring visual method in the field of educational leadership: co-creating understandings of educational leadership and authority in school organisations", Educational Management Administration and Leadership, Vol. 49 No. 7, doi: 10. 1177/17411432211030747.

Grimm, F. (2020), "The first teacher as the elephant in the room - forgotten and hidden teacher leadership perspectives in Swedish schools", Research in Educational Administration and Leadership, Vol. 5 No. 2, pp. 454-483.

$\mathrm{Gu}$, Q., Day, C., Walker, A. and Leithwood, K. (2018), "How successful secondary school principals enact policy", Leadership and Policy in Schools, Vol. 17 No. 3, pp. 327-331.

Gunter, H. (2016), New Public Management and the Reform of Education: European Lessons for Policy and Practice, Routledge, Abingdon.

Höog, J., Johansson, O. and Olofsson, A. (2005), "Successful principalship: the Swedish case”, Journal of Educational Administration, Vol. 43 No. 6, pp. 595-606.
Democratic governing ideals 
JEA

60,3

Johansson, O. and Ärlestig, H. (2022), "Policy implementations in schools, about the chain of command and its intervening spaces", in Nir, A.E. (Ed.), School Leadership in the 21st Century: Challenges and Coping Strategies, Nova Science Publishers, New York forthcoming.

Lawn, M. and Lingard, B. (2002), "Constructing a European policy space in education: governance: the role of transnational policy actors", European Educational Research Journal, Vol. 1 No. 2, pp. 290-307.

Leithwood, K.A. and Azah, V. (2017), "Characteristics of high- preforming schools districts", Leadership and Policy in Schools, Vol. 16 No. 1, pp. 27-53.

Leithwood, K.A., Louis, K.S., Anderson, S.E. and Knapp, M.S. (2012), Linking Leadership to Student Learning, Jossey-Bass, San Francisco.

Leo, U. (2013), "Rektorer ska, bör och gör - normer som påverkar rektorer [Principals shall, ought and do - norms that affect principals]", in Johansson, O. and Svedbergs, L. (Eds), To Lead towards the School Objectives, in Swedish], Gleerups, Malmö.

Louis, K. and Lee, M. (2016), "Teachers' capacity for organizational learning: the effects of school culture and context", School Effectiveness and School Improvement, Vol. 27 No. 4, pp. 534-556.

Louis, K. and Smith, B.A. (1991), "Restructuring, teacher engagement and school culture: perspectives on school reform and the improvement of teacher's work", School Effectiveness and School Improvement, Vol. 2 No. 1, pp. 34-52.

Louis, K.S. (2013), Organizing for School Change, Routledge, London.

Lundahl, L. (2012), "Educational theory in an era of knowledge capitalism", Studies in Philosophy and Education, Vol. 31 No. 3, pp. 215-226.

Lundgren, U.P. (2012), "En gemensam skola - utbildning blir en nödvändighet [A common school education becomes a necessity]”, in Lundgren, U.P., Säljö, R. and Lidberg, C. (Eds), Learning, School and Bildung - Basic Texts for Teachers, in Swedish], Natur \& Kultur, Stockholm.

Moos, L. and Paulsen, J.M. (2016), School Boards in the Governance Process, Springer, Cham.

Murphy, J. and Louis, K.S. (2018), Positive School Leadership: Building Capacity and Strengthening Relationships, Teachers College Press, New York.

Norqvist, L. and Ärlestig, H. (2020), "Systems thinking in school organizations - perspectives from various leadership levels", Journal of Educational Administration, Vol. 59 No. 1, pp. 77-93.

Ozga, J., Dahler-Larsen, P., Segerholm, C. and Simola, H. (2011), Fabricating Quality in Education: Data and Governance in Europe, Routledge, London.

Pashiardis, P. and Johansson, O. (2016), Successful School Leadership International Perspectives, Bloomsbury, London.

Pashiardis, P. and Johansson, O. (2021), "Successful and effective schools: bridging the gap", Educational Management, Administration and Leadership, Vol. 49 No. 5, pp. 690-707, doi: 10. 1177/1741143220932585.

Pressman, J.L. and Wildavsky, A.B. (1984), Implementation: How Great Expectations in Washington Are Dashed in Oakland: or, Why It's Amazing that Federal Programs Work at All, This Being a Saga of the Economic Development Administration as Told by Two Sympathetic Observers Who Seek to Build Morals on a Foundation of Ruined Hopes, University of California Press, Berkeley.

Rothstein, B. (2000), Politik Som Organisation [Politics as Organization, in Swedish], SNS Förlag, Stockholm.

Sannerstedt, A. (2000), "Implementering -hur politiska beslut genomförs i praktiken. I B. Rothstein, (red). Politik som organisation [Implementation - how political decisions come into practice", in Rothstein, B. (Ed.), Politics as Organization, in Swedish, SNS Förlag, Stockholm.

Shaked, H. and Schechter, C. (2017), Systems Thinking for School Leaders: Holistic Leadership for Excellence in Education, Springer, Cham. 
SOU (2015:22), Rektor Och Styrkedjan [The Principal and the Governing Chain], Ministry of Education, Stockholm.

Stoll, L. and Louis, K.S. (2007), Professional Learning Communities: Divergence, Depth and Dilemmas, McGraw-Hill/Open University Press, Maidenhead.

Democratic governing ideals

Timperley, H. (2011), Realizing the Power of Professional Learning, Open University Press, London.

Trujillo, T., Möller, J., Jensen, R., Espinoza Kissell, R. and Larsen, E. (2021), "Images of educational leadership: how principals make sense of democracy and social justice in two distinct policy contexts", Educational Administration Quarterly, Vol. 57 No. 2, pp. 1-34.

Weick, K.E. (1976), "Educational organizations as loosely coupled systems", Administrative Science Quarterly, Vol. 21 No. 1, pp. 1-19.

\section{Corresponding author}

Helene Ärlestig can be contacted at: helene.arlestig@umu.se

For instructions on how to order reprints of this article, please visit our website:

www.emeraldgrouppublishing.com/licensing/reprints.htm

Or contact us for further details: permissions@emeraldinsight.com 